\title{
Primary Bone Lymphoma in Axial Skeleton in a Middle-Aged Female Presented as Recurrent Anemia
}

\author{
Tala Batia Mohamed A. Yassin Deena S. Mudawi Omnia A. Hamid \\ Ahmed M.A. Abdalhadi \\ Hamad Medical Corporation, Doha, Qatar
}

\section{Keywords}

Primary bone lymphoma · Non-Hodgkin's lymphoma · Diffuse large B-cell lymphoma

\begin{abstract}
Primary bone lymphoma (PBL) is a peculiar extranodal presentation of non-Hodgkin's lymphoma. Primary bone diffuse large B-cell lymphoma ( $D L B C L)$ is the most common pathological type, comprising about $80 \%$ of PBL. The diagnosis of PBL depends on the combined clinical examination and imaging studies and is confirmed with immunohistochemical examination. Due to the rarity of this disease, more relative studies and case reports are needed to provide insight into this obscure lymphoproliferative malignancy. Here, we report one rare case of primary bone DLBCL involving the axial skeleton in a 37-year-old female.
\end{abstract}

\section{(c) 2020 The Author(s).}

Published by S. Karger AG, Basel

\section{Case Presentation}

In a 37-year-old woman with no chronic illnesses, initially diagnosed in Pakistan in May 2015 with diffuse large B-cell lymphoma (DLBCL) stage IV-E with axial bone marrow involvement and stomach involvement by PET-CT scan, no histopathological examination was performed.

She received a total of 6 cycles R-DA-EPOCH (dose-adjusted etoposide, prednisone, vincristine, cyclophosphamide, doxorubicin, and rituximab) and 5 cycles of triple IT (methotrexate, cytarabine, hydrocortisone), the last chemotherapy in October 2016, with a post-4th cycle interim and end of treatment PET-CT scans which showed complete metabolic remission. 
She was followed up until March 2019, when she presented with recurrent severe anemia requiring multiple blood transfusions without a history of GI bleeding. The physical examination was unremarkable.

PET-CT was done and showed diffuse increased bone marrow activity, few nonspecific normal-sized mildly enlarged hypermetabolic left iliac, left lower cervical, and thoracic inlet lymph nodes. Bone marrow biopsy was done and was consistent with relapsed DLBCL (monocytic B cells approximately $3 \%$ with immunophenotypic profile consistent with VD5/CD10negative mature B-cell neoplasm). The Fluorescence in situ hybridization study showed normal BCL6, IGH/BCL2, MYC.

She was started on salvage chemotherapy R-DHAP*, completed 3 cycles to complete remission, followed by BEAM* and ASCT*, which was complicated by an invasive mixed fungal infection and persistent pancytopenia.

\section{Discussion}

According to the World Health Organization classification of tumors of the soft tissue and bone in 2013 [1], primary bone lymphoma (PBL) is defined as a single skeletal lymphoma with or without regional lymph node involvement and multiple bone lesions without visceral or lymph node involvement. Its underlying causes are still largely unknown.

According to rare previous reports [2-7], PBL patients generally have localized bone pain, soft tissue swelling, and possibly a palpable lump in the site of the lesion. It commonly develops in patients aged between 20 and 50 years, shows a male preponderance, and the morbidity rate of males is slightly higher than that of females. The preferred site of PBL is the femur, accounting for $29 \%$ of all cases; other sites include the pelvis, humerus, skull and neck, and the tibia $[8,9]$. The pooled statistical analysis in the IELSG-14 study shows a low incidence of primary DLBCL bone lymphoma involving the forearm (5.6\%) in PBL patients.

Our patient first presented with recurrent anemia, no localized bone pain, and was found to have axial skeleton involvement.

The clinical manifestations and imaging are nonspecific with limitations in distinguishing PBL from other primary bone tumors such as Ewing's sarcoma, osteogenic sarcoma, and chondrosarcoma.

The majority of patients present with bone pain which is not relieved by rest. A palpable mass due to soft tissue extension of the bony disease is seen in about half of the cases [10]. Swelling, pathological fractures, cord compression, and systemic "B" symptoms (i.e., fever, weight loss, night sweats) may also be present at the time of diagnosis [11]. Occasionally, symptoms may persist for many months before the patient seeks medical attention.

DLBCL is the most common pathological type either primarily or secondarily infiltrating the skeleton, accounting for about $70-80 \%$ of all PBL, with rare to anecdotal occurrences of follicular, marginal zone, lymphoplasmacytic, anaplastic large cell, natural killer/T-cell, Burkitt, and Hodgkin lymphomas. Tumor cells are generally immunoreactive for the B-cell markers CD20, CD21, CD45, and CD79a [12, 13].

A series of 160 patients with primary bone DLBCL, using an immunohistochemistrybased predictor, reported that $90 \%$ of cases were of germinal center derivation. MYC rearrangements were identified in 5 of 17 cases and BCL2 rearrangement in 6 of 8 cases [14]. A tissue microarray study of 63 cases of primary DLBCL of bone revealed that 42 were of germinal center and 21 of nongerminal center derivation [15]. Fluorescence in situ hybridization performed on 32 cases reported rearrangements of BCL2 and MYC in 9 and 3 specimens, respectively. One case showed both BCL2 and MYC rearrangements, and no cases had rearrangement of BCL6. 
Diagnostic samples obtained by surgical procedure and immunohistochemical tests are indispensable for clinicoradiological confirmation of PBL and for differential diagnosis. Other surgical procedures, especially excision of lesions, should be avoided whenever possible, unless the involved weight-bearing bones are destroyed extensively or pathological fractures are present in bone lesions $[16,17]$.

As a result of the rarity of this disease, randomized trials addressing treatment alternatives for PBL are not available. Most retrospective studies report the results of patients treated with various therapeutic modalities. Historically, PBL was treated with radiotherapy alone with good local control (87-100\%) [18]. However, distant relapse rates were often disappointing, as more than $50 \%$ of patients failed systemically. Currently multiagent chemotherapy with or without radiation therapy is preferred resulting in approximately $70 \%$ of patients surviving for 5 years.

An analysis of the Surveillance, Epidemiology, and End Results (SEER) database included 1,500 adult patients with PBL diagnosed from 1973 through 2005 [19]. Five- and 10-year overall survival rates were 58 and $45 \%$, respectively. On multivariate analysis only younger age and localized disease were independent predictors of survival. Five-year survival rates were 87,74 , and $45 \%$ for those patients diagnosed at $<30,30-59$, and $>60$ years, respectively.

\section{Chemotherapy with or without Radiation}

Multiagent chemotherapy with or without radiation therapy is the preferred treatment of adults with PBL. Given that the majority of PBL are aggressive B cell lymphomas, patients are typically treated with anthracycline-based, multiagent chemotherapy, such as CHOP (cyclophosphamide, doxorubicin, vincristine, prednisone) with the addition of the anti-CD20 antibody rituximab. The use of radiotherapy is controversial, though a number of studies prior to the use of rituximab demonstrate a benefit of combined modality therapy. In patients with unifocal disease, consolidative involved-field radiotherapy is reasonable, but should be individualized with particular attention to the location of disease. Radiation to areas, such as the pelvis, which contain significant marrow production, should be carefully considered. A dose of 30-36 Gy is reasonable in patients who attain a complete response following chemotherapy. A higher dose (e.g., $40 \mathrm{~Gy}$ ) is offered to patients with an indeterminate response (e.g., those with a positive PET that may represent active tumor or healing bone).

\section{Surgical Intervention}

The role of surgery is generally limited to diagnostic biopsy and stabilization of a pathological fracture. Orthopedic management is important during the treatment and recovery period because the potential for fracture persists until there is complete bone healing. Rarely, patients with involvement of the weight-bearing bones may require internal stabilization or bracing until bone healing occurs.

\section{Conclusion}

PBL itself is a rare tumor about which only few studies having been done. Therefore, its varied clinical and histopathological profiles are still to be fully explored.

We reported our experience with a patient with PBL with an unusual presentation and an unusually complicated course after multiple chemotherapy lines, who is still under treatment and being followed up after relapse. 
Batia et al.: PBL in Axial Skeleton in a Middle-Aged Female

\section{Acknowledgment}

The authors would like to thank Qatar National Library-QNL for funding this publication. We would also like to thank Internal Medicine Residency Program at Hamad Medical Corporation for supporting research.

\section{Statement of Ethics}

Case approved by HMC Medical Research Center. The patient gave her written informed consent for her case to be published.

\section{Disclosure}

The authors report no conflicts of interest in this work.

\section{Authors Contributions}

Tala Batia: writing and editing.

Mohamed A. Yassin: writing and editing.

Other authors: clinical care.

\section{References}

1 Rosenberg AE. WHO classification of soft tissue and bone, fourth edition: summary and commentary. Curr Opin Oncol. 2013;25(5):571-3.

2 Marina V, Milena R, Vesna P, Sladana P, Vera A. Complementary roles of bone scintigraphy and MR imaging in the detection and long-term follow-up of primary non-Hodgkin's bone lymphoma in a child-case report. Skeletal Radiol. 2015;44(6):863-8.

3 Mandal PK, Baul S, Dolai TK. Primary bone lymphoma with multifocal osteolytic lesions: a rare case report with review of literature. Blood Res. 2015;50(4):256-60.

4 Inklab M, Steingart RH, Freeman JK. Primary lymphoma of bone presenting as spindle cell neoplasm of the vertebral body: a case report and review of the literature. Case Rep Hematol. 2015;2015:518307.

5 Zhou HY, Gao F, Bu B. Primary bone lymphoma: a case report and review of the literature. Oncol Lett. 2014;8(4):1551-6.

6 Liu M, Liu B, Han F, Song Y. Primary bone lymphoma of the left radius: a case report and related literature review. Eur J Med Res. 2014;19(1):19.

7 Kishan Prasad HL, Jayaprakash Shetty K, Mathias L, Sunil Kumar Y, Permi HS, Rao C. Primary bone lymphoma of humerus diagnosed by FNAC - a rare case report. Indian J Surg Oncol. 2013;4(3):316-9.

8 Messina C, Christie D, Zucca E, Gospodarowicz M, Ferreri AJ. Primary and secondary bone lymphomas. Cancer Treat Rev. 2015;41(3):235-46.

9 Bruno Ventre M, Ferreri AJ, Gospodarowicz M. Clinical features, management, and prognosis of an international series of 161 patients with limited-stage diffuse large B-cell lymphoma of the bone (the IELSG-14 study). Oncologist. 2014;19(3):291-8.

10 Mulligan ME, McRae GA, Murphey MD. Imaging features of primary lymphoma of bone. AJR Am J Roentgenol. 1999;173:1691.

11 Bruno Ventre M, Ferreri AJ, Gospodarowicz M. Clinical features, management, and prognosis of an international series of 161 patients with limited-stage diffuse large B-cell lymphoma of the bone (the IELSG-14 study). Oncologist. 2014;19:291.

12 Pettit CK, Zukerberg LR, Gray MH. Primary lymphoma of bone. A B-cell neoplasm with a high frequency of multilobated cells. Am J Surg Pathol. 1990;14(4):329-34.

13 Huebner-Chan D, Fernandes B, Yang G, Lim MS. An immunophenotypic and molecular study of primary large B-cell lymphoma of bone. Mod Pathol. 2001;14(10):1000-7. 
14 Li X, Xu-Monette ZY, Yi S. Primary bone lymphoma exhibits a favorable prognosis and distinct gene expression signatures resembling diffuse large B-cell lymphoma derived from centrocytes in the germinal center. Am J Surg Pathol. 2017;41:1309.

15 Lima FP, Bousquet M, Gomez-Brouchet A. Primary diffuse large B-cell lymphoma of bone displays preferential rearrangements of the c-MYC or BCL2 gene. Am J Clin Pathol. 2008;129:723.

16 Liu YC, Gau JP, Yu YB. Prognostic factors and treatment efficacy in patients with primary diffuse large B-cell lymphoma of the bone: single institute experience over 11 years. Intern Med. 2014;53(2):95-101.

17 Cirakli A, Elli M, Dabak N, Canbaz Tosun F, Dagdemir A, Cirakli S. Evaluation of primary bone lymphoma and the importance of positron emission tomography. Acta Orthop Traumatol Turc. 2014;48(3):371-8.

18 Cai L, Stauder MC, Zhang YJ. Early-stage primary bone lymphoma: a retrospective, multicenter Rare Cancer Network (RCN) Study. Int J Radiat Oncol Biol Phys. 2012;83:284.

19 Jawad MU, Schneiderbauer MM, Min ES. Primary lymphoma of bone in adult patients. Cancer. 2010;116:871. 